Original Research Article

\title{
Biochemical and histopathological assessment of atorvastatin-loaded nanoemulsion effectiveness in Rats
}

\author{
Khadijah S. Balamash*, Mona S. Al-ddyni
}

Department of Biochemistry, Faculty of Science, King Abdulaziz University, Jeddah, Saudi Arabia

Received: 10 November 2017 Accepted: 24 December 2017

\section{*Correspondence to:}

Dr. Khadijah S. Balamash, Email: kbalamash@kau.edu.sa

Copyright: (C) the author(s), publisher and licensee Medip Academy. This is an openaccess article distributed under the terms of the Creative Commons Attribution NonCommercial License, which permits unrestricted noncommercial use, distribution, and reproduction in any medium, provided the original work is properly cited.

\begin{abstract}
Background: Atorvastatin (ATV), a lipid lowering agent, has low solubility and poor dissolution affects its oral bioavailability. Nanoemulsion (NE) has been developed to improve the delivery of therapeutic agents. This study was aimed to assess the ability of the NE in enhancing ATV bioavailability and minimizing its side effects in hyperlipidemic rats.

Methods: Thirty-five rats divided into seven groups were utilized in this study. Hyperlipidemia was induced by feeding rats high fat diet (HFD) for 3 months. The antihyperlipidemic activity of 10 and $20 \mathrm{mg} / \mathrm{kg}$ of ATV loaded in two different delivery systems; nanoemulsion (10\% and 20\% ATV-LNE) or in water (10\% and $20 \%$ ATV-sol), were investigated. At the end of the experiment, body weight, serum and plasma biochemical parameters (lipid profile, glucose, insulin, liver and kidney functions, oxidative stress markers were assessed. Liver and kidney were histopathologically examined. The physical characteristics of NE were determined by the Zetasizer (the z-average diameter and zeta potential).

Results: 20\% ATV-LNE had the smallest nanoparticles $(38.12 \pm 6.71 \mathrm{~nm})$ whereas it had the largest zeta negative potential of $-26.8 \pm 4.16 \mathrm{mV}$. The serum biochemical results and the histopathological examination revealed that treatment with 20\% ATV-LNE improved the lipid profile by significantly increasing HDL and decreasing cholesterol and low-density lipoprotein. Both 10 and 20\% ATVLNE reduced serum glucose level compared to other used formulas.

Conclusions: NE formulas have the potential to improve the bioavailability and efficacy of ATV and reduce its side effects.
\end{abstract}

Keywords: Atorvastatin, Cholesterol, Fat, Kidney functions structure, Liver, Nanoparticles

\section{INTRODUCTION}

Hyperlipidemia, also defined as dyslipidemia or hypercholesterolemia, is the most important risk factor of atherosclerosis and is associated with increased oxidative stress with subsequent production of oxygen free radicals. ${ }^{1}$ Atherosclerosis is the major cause of cardiovascular diseases that caused by the accumulation of fat in the walls of arteries. ${ }^{2}$ Statins, the major anti-hyperlipidemic agents for the treatment of elevated plasma cholesterol, are competitive inhibitors of 3-hydroxy-3methylglutarylcoenzyme A (HMG-CoA) reductase. It has revolutionized the treatment of hyperlipidemia, They are being also esteemed for their good tolerance. ${ }^{3}$ The most disturbing adverse effects associated with statins were asymptomatic increase in hepatic enzymes and musculoskeletal disorders like myalgia, myopathy, and rhabdomyolysis. ${ }^{4}$ Atorvastatin (ATV) is the leading drug among statins. ${ }^{5}$ The oral absorption of ATV is $30 \%$ and bioavailability is only $12 \% .^{6}$ As with other HMG-CoA reductase inhibitors, the most frequently reported adverse events associated with ATV are gastrointestinal effects. ${ }^{7}$

In controlled drug delivery systems (DDS) the drug can be transported to the site of action, hence, its effect on vital tissues and minimized undesirable side effects. ${ }^{8}$ In addition, DDS protects the drug from rapid degradation or 
clearance and enhances drug concentration in target site; therefore, lower doses of drug are required. ${ }^{9}$

Nanoparticles (structures smaller than 100nm) have a great potential as drug carriers. ${ }^{10}$ Nanoemulsions (NE) are oilin-water $(\mathrm{O} / \mathrm{W})$, water-in-oil $(\mathrm{W} / \mathrm{O})$ colloidal dispersion of two immiscible liquids stabilized using an appropriate surfactant. ${ }^{11}$ It is characterized by stability and clarity and kinetically stable. The NEs are composed from three main components: Oil, Surfactant/Cosurfactant and Aqueous phase. ${ }^{12}$ Some researchers have been reported that used of NEs formulations in improving the dissolution and bioavailability of ATV. In the study of Kadu appeared that self-emulsifying drug delivery systems (SEDDS) to be an interesting approach to improve problems associated with oral delivery of ATR and can be regarded as a novel and commercially feasible alternative to current ATR formulations. ${ }^{13}$

The aim of this study was to evaluate the effectiveness of atorvastatin nanoemulsion as a carrier to enhance the oral bioavailability and drug release and to evaluate its hypolipidemic and antioxidative effects in hyperlipidemic rats.

\section{METHODS}

\section{Drugs}

Cholesterol (CHO) was purchased from HiMedia Laboratories Pvt. Ltd., Mumbai, India. Deoxycholic acid $\geq 98 \%$ (HPLC) was obtained from Sigma-Aldrich, St. Louis, MO, USA. Atorvastatin calcium (Lipitor) was a gift from Jamjoom Pharma, Jeddah, Saudi Arabia.

\section{Preparation of the Atorvastatin -loaded - nanoemulsion}

The NE formulation were prepared, as described by Alkhatib and AlBishi with some modifications. ${ }^{14}$ Different weights of cholesterol as an oil phase, Tris- $\mathrm{HCl}$ buffer $(\mathrm{pH}$ 7.22) as the aqueous phase, surfactant mixture of EU/SPC/SO, and 1-octanol as a co-surfactant were mixed. The mixture weight fraction of nanoemulsion formulation as shown in Figure 1. Atorvastatin-loaded-NE (ATVLNE) formulas were prepared according to Chouksey. ${ }^{15}$

\section{Characterization of ATV-LNE using a scanning electron microscope (SEM)}

The particle size and morphology analysis were carried out using SEM (Malvern Instruments Ltd, U.K). Nanoemulsion specimens for SEM was prepared as described by Alkhatib and Al-qaidi specimens for the SEM was as described. ${ }^{16}$

\section{Experimental design}

Thirty-five male Wister rats with body weight (BW) ranged from 150-200gm were obtained from King Fahad Medical Research Center (KFMRC), King Abdulaziz
University, Jeddah, Saudi Arabia. They were divided into seven groups $(n=5)$ as shown in Figure 1.

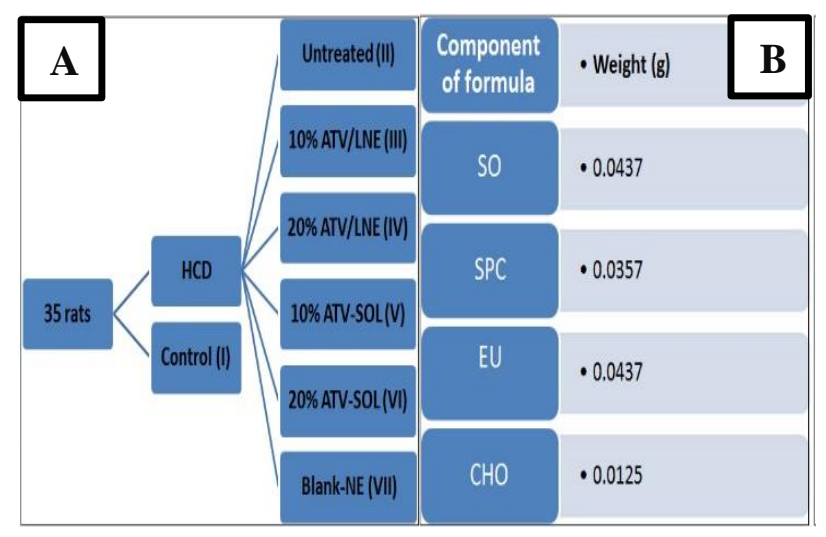

Figure 1: (A): Study groups. HCD; High cholesterol diet, ATV; Aatorvastatin, LNE; loaded with nanoemulsion, NE; nanoemulsion, SOL. (B): The nanoemulsion formula prepared at weight percentages of the mixture, EU/SPC/SO.

The control group (I) received the standard rat pellets while hyperlipidemia was induced in the other 6 groups by administration of high fat diet (HFD) for three months. The HFD comprised $1 \%$ cholesterol, $0.2 \%$ bile salts and $20 \%$ hydrogenated coconut oil. ${ }^{17}$ After three months, treatment were started orally in five groups and continued for 15 days. Body weight (BW) of each rat was measured weekly during the experiment. At the end of the experimental period, all the rats were kept fasting for $12 \mathrm{~h}$ then rats were anesthetized with ether and blood samples were obtained from the intraorbital vein. The blood was centrifuged at $3000 \mathrm{rpm}$ for $10 \mathrm{~min}$ and the serum was stored at $-80^{\circ} \mathrm{C}$ until biochemical analysis.

\section{Biochemical assessment}

The lipid profile included; CHO, triglycerides (TG), low density lipoprotein (LDL), high density lipoprotein (HDL) was assessed. Serum glucose, total protein (TP), liver function testes including; Alkaline Phosphatase (ALP), Aspartate Aminotransferase (AST), Alanine Aminotransferase (ALT) and kidney function tests including; Creatinine (CRE) and uric acid level were measured. Serum insulin Malondialdehyde (MDA) and Total Antioxidant Capacity (TAC) were measured. These parameters were assessed at King Abdul-Aziz University Hospital, Jeddah, Saudi Arabia.

\section{Histopathological assessment}

After collecting the blood samples from the anesthetized rats, they were sacrificed by cervical dislocation then liver and kidney were dissected out, washed with saline, dried, weighted, fixed in $10 \%$ neutral buffered formalin and processed for histopathological examination after being stained with haematoxylin and eosin ( $\mathrm{H}$ and $\mathrm{E})$. 


\section{Statistical analysis}

Statistical analysis was performed using Megastate Excel (version 10.3, Butler University). One-way factor analysis of variance (ANOVA) was performed. The results were expressed as mean value \pm standard deviation $(\overline{\mathrm{x}} \pm \mathrm{SD})$. The significant difference was considered when $\mathrm{P}$ value $<0.05$.

\section{RESULTS}

\section{Characterization of ATV-LNEs}

The droplet size and morphology analysis were carried out using SEM. The droplets of all formulations loaded NE took a spherical shape (Figure 2). The physical characteristics of all ATV-LNEs are showed in Figure 2 and Table 1.
Table 1: The physical characteristics of the nanoparticles of the NE formulations.

\begin{tabular}{|lllll|}
\hline Formulation & $\begin{array}{l}\text { Z-average } \\
\text { diameter }(\mathbf{n m})\end{array}$ & PDI & $\begin{array}{l}\text { Zeta potentia } \\
(\mathbf{m V})\end{array}$ \\
\hline BL-NE & $119.2 \pm 16.17$ & 0.136 & $-14.5 \pm 9.26$ \\
\hline $10 \%$ & ATV- & $108.6 \pm 19.72$ & 0.128 & $-13.5 \pm 8.30$ \\
LNE & & $\mathrm{P}=0.4265$ & & $\mathrm{P}=0.8768$ \\
\hline $20 \%$ & ATV- & $\begin{array}{l}38.12 \pm 6.71 \\
\mathrm{P} 1=0.0006\end{array}$ & 0.176 & $\begin{array}{l}\mathrm{P} 1=0.0937 \\
\text { LNE }\end{array}$ \\
& & P2=0.0013 & & $\mathrm{P} 2=0.0749$ \\
\hline
\end{tabular}

$\overline{\mathrm{x}} \pm \mathrm{SD}$. One-factor ANOVA and measuring the p-values for the pairwise t-test was used; $\mathrm{P}$ value of BL-NE versus $10 \%$ ATVLNE; P1 value of BL-NE versus 20\% ATV-LNE; P2 value of $10 \%$ ATV-LNE versus 20\% ATV-LNE; P value $<0.05$ is considered significant
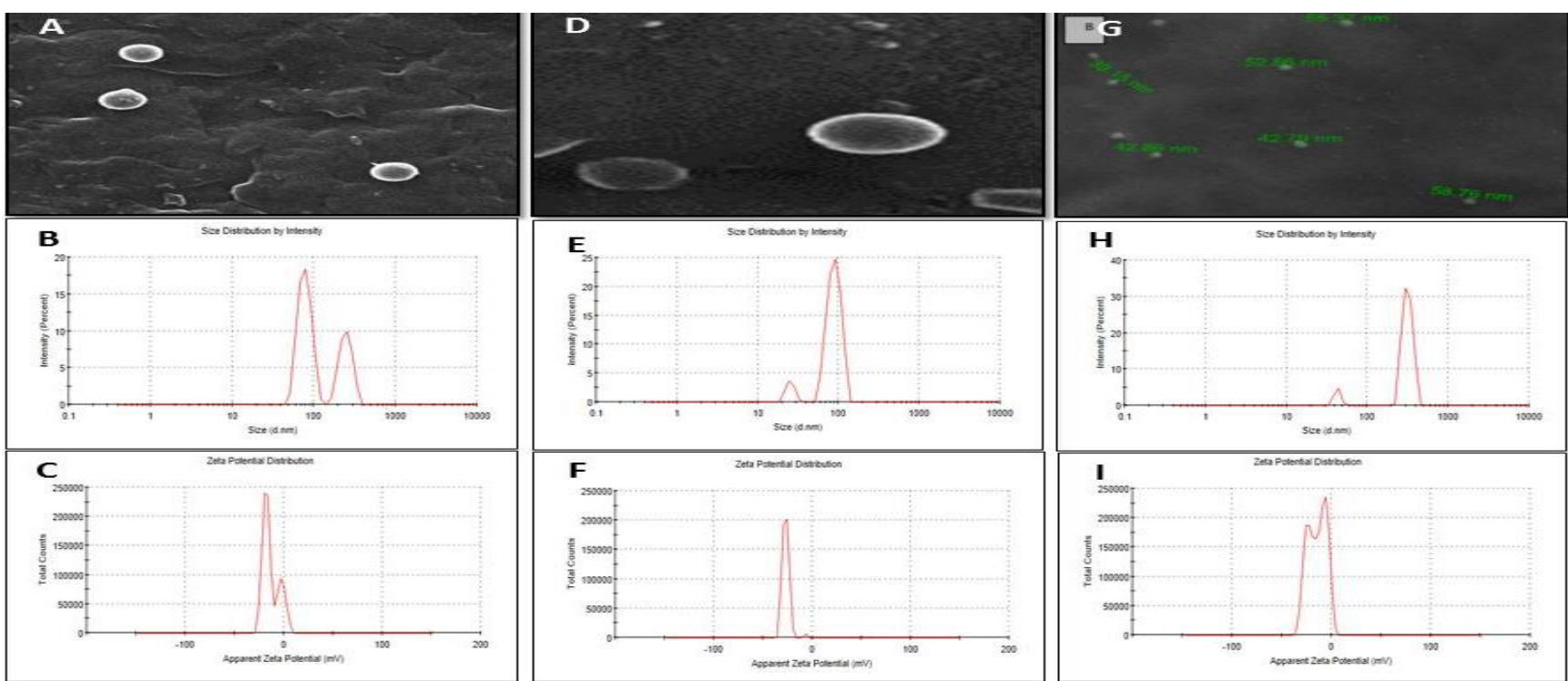

Figure 2: Scanning electron microphotograph and particle size and zeta potential distribution of 10\% ATV-LNE (A, B, C), $20 \%$ ATV-LNE (D, E, F) and Blank (G, H, I).

\section{Body weight change}

Compared to the control group, only the $20 \%$ ATV-sol is highly significantly lower in the \% of BW change Table 2. A significant increase in the liver/BW ratio of the untreated group compared to the control. A significant increase in the Liver/BW ratio of $10 \%$ ATV-Sol and 20\% ATV-LNE compared to the control group were found. The effect of the drug formulations on the ratio of kidney weight to the body weight for $20 \%$ ATV-Sol, Blank-NE and 20\% ATVLNE groups showed least significant changes in kidney compared to the control group (Table 2).

\section{Lipid profile and serum glucose}

All treated groups showed decrease in CHO levels except $10 \%$ ATV-LNE group which cause significant increase in
CHO compared to the control group. It is noteworthy to mention that treatment with $20 \%$ ATV-LNE was the most effective formulation against the increased in total cholesterol (Table 3). The levels of TG of all the treated groups were comparable to the control group. Regarding the LDL levels, all treated groups showed no significant change compared to the normal group except $10 \%$ ATVLNE was significantly higher than 20\% ATV-LNE and BL-NE groups (Table 3). Serum glucose level increased in untreated group compared to control. Serum glucose levels of $10 \%$ ATV-LNE were found to be highly significant lower than untreated group.

It is noteworthy to mention that treatment with both 10\%ATV-LNE and 20\% ATV-LNE caused the most reduction in serum glucose levels, although this change was not significant (Table 3). 
Table 2: The effect of the drug formulations on the body and organs weight (g) in all groups.

\begin{tabular}{|c|c|c|c|c|c|c|}
\hline Group & $\begin{array}{l}\text { Initial } \\
\text { weight (g) }\end{array}$ & $\begin{array}{l}\text { Final weight } \\
\text { (g) }\end{array}$ & $\begin{array}{l}\% \text { change in } \\
\text { body weight }\end{array}$ & $\%$ liver weight & $\begin{array}{l}\text { \% r-kidney } \\
\text { weight }\end{array}$ & $\begin{array}{l}\% \text { l-kidney } \\
\text { weight }\end{array}$ \\
\hline Control & $116.6 \pm 3$ & $349.4 \pm 28.8$ & $199.7 \%$ & $11.45 \pm 1.93$ & $1.19 \pm 0.14$ & $1.18 \pm 0.12$ \\
\hline Untreated & $183.6 \pm 9.8$ & $426.2 \pm 64.4$ & $\begin{array}{l}132.1 \% \\
P=0.7937\end{array}$ & $\begin{array}{l}16.51 \pm 1.54 \\
P=0.0010\end{array}$ & $\begin{array}{l}1.14 \pm 0.15 \\
P=0.5518\end{array}$ & $\begin{array}{l}1.10 \pm 0.17 \\
P=0.3123\end{array}$ \\
\hline $10 \%$ ATV-LNE & $147.2 \pm 2.4$ & $338.6 \pm 52.5$ & $\begin{array}{l}130 \% \\
P=0.1614 \\
P 1=0.2502\end{array}$ & $\begin{array}{l}14.26 \pm 1.33 \\
P=0.0500 \\
P 1=0.1133\end{array}$ & $\begin{array}{l}1.09 \pm 0.07 \\
P=0.2297 \\
P 1=0.5367\end{array}$ & $\begin{array}{l}1.05 \pm 0.04 \\
P=0.1194 \\
P 1=0.5684\end{array}$ \\
\hline $20 \%$ ATV-LNE & $175.6 \pm 15.6$ & $363.2 \pm 73.4$ & $\begin{array}{l}106.8 \% \\
P=0.1276 \\
P 1=0.2021\end{array}$ & $\begin{array}{l}17.75 \pm 4.27 \\
P=0.0001 \\
P 1=0.3745\end{array}$ & $\begin{array}{l}1.31 \pm 0.21 \\
\mathrm{P}=0.0002 \\
\mathrm{P} 1=0.0562\end{array}$ & $\begin{array}{l}1.33 \pm 0.15 \\
P=0.0693 \\
P 1=0.0069\end{array}$ \\
\hline $10 \%$ ATV-sol & $165.0 \pm 11.6$ & $379.8 \pm 53.7$ & $\begin{array}{l}130.2 \% \\
P=0.5368 \\
P 1=0.7206\end{array}$ & $\begin{array}{l}16.54 \pm 1.84 \\
P=0.0009 \\
P 1=0.9804\end{array}$ & $\begin{array}{l}1.20 \pm 0.17 \\
P=0.9268 \\
P 1=0.4928\end{array}$ & $\begin{array}{l}1.16 \pm 0.20 \\
P=0.7655 \\
P 1=0.4727\end{array}$ \\
\hline $20 \%$ ATV-sol & $193.0 \pm 13$ & $306.8 \pm 11.7$ & $\begin{array}{l}59 \% \\
\mathrm{P}=0.0003 \\
\mathrm{P} 1=0.0006\end{array}$ & $\begin{array}{l}11.37 \pm 1.37 \\
P=0.9540 \\
P 1=0.0008\end{array}$ & $\begin{array}{l}0.94 \pm 0.10 \\
P=0.0061 \\
P 1=0.0253\end{array}$ & $\begin{array}{l}0.90 \pm 0.05 \\
P=0.0012 \\
P 1=0.0161\end{array}$ \\
\hline Blank-NE & $130.2 \pm 4.1$ & $322.8 \pm 28.8$ & $\begin{array}{l}147.9 \% \\
P=0.1730 \\
P 1=0.2663\end{array}$ & $\begin{array}{l}11.9 \pm 1.28 \\
P=0.7457 \\
P 1=0.0023\end{array}$ & $\begin{array}{l}1.02 \pm 0.05 \\
P=0.0474 \\
P 1=0.1524\end{array}$ & $\begin{array}{l}0.99 \pm 0.04 \\
P=0.0228 \\
P 1=0.1784\end{array}$ \\
\hline
\end{tabular}

$\overline{\mathrm{x}} \pm \mathrm{SD}$. One-factor ANOVA and measuring the p-values for the pairwise t-test was used; P value versus control; P1 value versus untreated group; $\mathrm{P}$ value $<0.05$ is considered significant.

Table 3: Lipid profile, serum glucose and serum insulin in all groups.

\begin{tabular}{|c|c|c|c|c|c|c|}
\hline Group & $\begin{array}{l}\text { CHO } \\
(\mathrm{mmol} / \mathrm{L})\end{array}$ & $\begin{array}{l}\text { TG } \\
(\mathrm{mmol} / \mathrm{L})\end{array}$ & $\begin{array}{l}\text { LDL } \\
(\mathrm{mmol} / \mathrm{L})\end{array}$ & $\begin{array}{l}\text { HDL } \\
(\mathrm{mmol} / \mathrm{L})\end{array}$ & $\begin{array}{l}\text { GLU } \\
(\mathrm{mmol} / \mathrm{L})\end{array}$ & $\begin{array}{l}\text { Serum insulin } \\
(\mathrm{ng} / \mathrm{ml})\end{array}$ \\
\hline Normal & $1.54 \pm 0.09$ & $0.45 \pm 0.08$ & $0.31 \pm 0.04$ & $1.41 \pm 0.19$ & $6.14 \pm 1.167$ & $1.21 \pm 0.59$ \\
\hline \multirow{2}{*}{ Untreated } & $1.78 \pm 0.25$ & $0.67 \pm 0.30$ & $0.44 \pm 0.15$ & $1.53 \pm 0.17$ & $7.46 \pm 1.119$ & $2.25 \pm 1.07$ \\
\hline & $\mathrm{P}=0.0439$ & $\mathrm{P}=0.0508$ & $\mathrm{P}=0.1193$ & $\mathrm{P}=0.1554$ & $\mathrm{P}=0.1554$ & $\mathrm{P}=0.2250$ \\
\hline \multirow{3}{*}{$10 \%$ ATV-NE } & $1.80 \pm 0.14$ & $0.60 \pm 0.19$ & $0.48 \pm 0.25$ & $1.56 \pm 0.21$ & $4.96 \pm 1.083$ & $1.78 \pm 1.72$ \\
\hline & $\mathrm{P}=0.0314$ & $\mathrm{P}=0.1663$ & $\mathrm{P}=0.0523$ & $\mathrm{P}=0.2024$ & $\mathrm{P}=0.2024$ & $\mathrm{P}=0.4975$ \\
\hline & $\mathrm{P} 1=0.8777$ & $\mathrm{P} 1=0.5406$ & $\mathrm{P} 1=0.6775$ & $\mathrm{P} 1=0.8742$ & $\mathrm{P} 1=0.0100$ & $\mathrm{P} 1=0.5845$ \\
\hline \multirow{3}{*}{$20 \%$ ATV-NE } & $1.46 \pm 0.16$ & $0.48 \pm 0.01$ & $0.30 \pm 0.10$ & $1.61 \pm 0.28$ & $5.92 \pm 2.123$ & $1.23 \pm 1.08$ \\
\hline & $\mathrm{P}=0.4956$ & $\mathrm{P}=0.7556$ & $\mathrm{P}=0.8447$ & $\mathrm{P}=0.8095$ & $\mathrm{P}=0.8095$ & $\mathrm{P}=0.9772$ \\
\hline & $\mathrm{P} 1=0.0091$ & $\mathrm{P} 1=0.0953$ & $\mathrm{P} 1=0.0819$ & $\mathrm{P} 1=0.6596$ & $\mathrm{P} 1=0.0996$ & $\mathrm{P} 1=0.2357$ \\
\hline \multirow{3}{*}{$10 \%$ ATV-Sol } & $1.51 \pm 0.19$ & $0.57 \pm 0.17$ & $0.35 \pm 0.08$ & $1.52 \pm 0.24$ & $8.20 \pm 1.528$ & $2.17 \pm 1.96$ \\
\hline & $\mathrm{P}=0.8009$ & $\mathrm{P}=0.2836$ & $\mathrm{P}=0.6422$ & $\mathrm{P}=0.0305$ & $\mathrm{P}=0.0305$ & $\mathrm{P}=0.2584$ \\
\hline & $\mathrm{P} 1=0.0252$ & $\mathrm{P} 1=0.3515$ & $\mathrm{P} 1=0.2651$ & $\mathrm{P} 1=0.9369$ & $\mathrm{P} 1=0.4200$ & $\mathrm{P} 1=0.9314$ \\
\hline \multirow{3}{*}{ 20\%ATV-Sol } & $1.56 \pm 0.27$ & $0.57 \pm 0.18$ & $0.40 \pm 0.10$ & $1.70 \pm 0.53$ & $7.60 \pm 1.654$ & $1.73 \pm 1.20$ \\
\hline & $\mathrm{P}=0.8810$ & $\mathrm{P}=0.2955$ & $\mathrm{P}=0.2860$ & $\mathrm{P}=0.1175$ & $\mathrm{P}=0.1175$ & $\mathrm{P}=0.5372$ \\
\hline & $\mathrm{P} 1=0.0601$ & $\mathrm{P} 1=0.3380$ & $\mathrm{P} 1=0.6077$ & $\mathrm{P} 1=0.3026$ & $\mathrm{P} 1=0.8780$ & $\mathrm{P} 1=0.5429$ \\
\hline \multirow{3}{*}{ Blank-NE } & $1.36 \pm 0.10$ & $0.48 \pm 0.13$ & $0.29 \pm 0.05$ & $1.64 \pm 0.10$ & $7.68 \pm 0.968$ & $3.05 \pm 1.16$ \\
\hline & $\mathrm{P}=0.1421$ & $\mathrm{P}=0.8075$ & $\mathrm{P}=0.7689$ & $P=0.1006$ & $\mathrm{P}=0.1006$ & $P=0.0367$ \\
\hline & $\mathrm{P} 1=0.0012$ & $\mathrm{P} 1=0.0835$ & $\mathrm{P} 1=0.0673$ & $\mathrm{P} 1=0.5500$ & $\mathrm{P} 1=0.8138$ & $\mathrm{P} 1=0.3484$ \\
\hline
\end{tabular}

$\overline{\mathrm{x}} \pm \mathrm{SD}$. One-factor ANOVA and measuring the $\mathrm{p}$-values for the pairwise $\mathrm{t}$-test was used; $\mathrm{P}$ value versus control; P1 value versus untreated group; $\mathrm{P}$ value $<0.05$ is considered significant.

\section{Liver functions}

The levels of TP were found not significantly changed in all studied group. ALP levels were significantly increased in untreated group compared to the control group. 10 and $20 \%$ ATV-sol treated group showed highly significant increase in ALP levels compared to control group (Table
4). It is repeated noteworthy to mention that treatment with both 10\%ATV-LNE and 20\% ATV-LNE caused the most reduction in serum glucose levels, although this change was not significant (Table 3). 
Table 4: Liver and kidney functions in all studied groups.

\begin{tabular}{|c|c|c|c|c|c|c|}
\hline Parameters & $\begin{array}{l}\text { TP } \\
(64.0- \\
82.0 \mathrm{~g} / \mathrm{L})\end{array}$ & $\begin{array}{l}\text { ALP } \\
(45.0-117.0 U / L)\end{array}$ & $\begin{array}{l}\text { ALT } \\
(12.0- \\
68.0 \mathrm{U} / \mathrm{L})\end{array}$ & $\begin{array}{l}\text { AST } \\
(15.0- \\
37.0 U / L)\end{array}$ & $\begin{array}{l}\text { CRE } \\
\text { (53.0- } \\
\text { 115.0umol/L) }\end{array}$ & $\begin{array}{l}\text { URC } \\
(155.0- \\
428.0 u m o l / L)\end{array}$ \\
\hline Control & $67.0 \pm 3.32$ & $139.0 \pm 10.42$ & $61.20 \pm 11.52$ & $113.75 \pm 4.97$ & $52.4 \pm 4.34$ & $53.00 \pm 8.25$ \\
\hline Untreated & $\begin{array}{l}69.0 \pm 3.61 \\
P=0.5141\end{array}$ & $\begin{array}{l}283.6 \pm 37.6 \\
P=0.0274\end{array}$ & $\begin{array}{l}116.0 \pm 25.15 \\
\mathrm{P}=0.0112\end{array}$ & $\begin{array}{l}115.25 \pm 20.4 \\
\mathrm{P}=0.0986\end{array}$ & $\begin{array}{l}60.0 \pm 4.47 \\
\mathrm{P}=0.0434\end{array}$ & $\begin{array}{l}55.00 \pm 14.30 \\
\mathrm{P}=0.7698\end{array}$ \\
\hline $10 \%$ ATV-LNE & $\begin{array}{l}66.2 \pm 5.22 \\
P=0.7934 \\
P 1=0.3627\end{array}$ & $\begin{array}{l}265.0 \pm 20.58 \\
P=0.0521 \\
P 1=0.7668\end{array}$ & $\begin{array}{l}112.5 \pm 24.02 \\
\mathrm{P}=0.0011 \\
\mathrm{P} 1=0.3593\end{array}$ & $\begin{array}{l}170.25 \pm 45.26 \\
\mathrm{P}=0.0004 \\
\mathrm{P} 1=0.0000\end{array}$ & $\begin{array}{l}49.0 \pm 3.16 \\
P=0.3519 \\
P 1=0.0434\end{array}$ & $\begin{array}{l}58.0 \pm 14.20 \\
P=0.4661 \\
P 1=0.6609\end{array}$ \\
\hline $20 \%$ ATV-LNE & $\begin{array}{l}69.0 \pm 6.89 \\
P=0.3627 \\
P 1=1.0000\end{array}$ & $\begin{array}{l}229.0 \pm 30.75 \\
P=0.1585 \\
P 1=0.3869\end{array}$ & $\begin{array}{l}111.0 \pm 37.75 \\
\mathrm{P}=0.0014 \\
\mathrm{P} 1=0.4162\end{array}$ & $\begin{array}{l}131.50 \pm 18.3 \\
\mathrm{P}=0.2122 \\
\mathrm{P} 1=0.0058\end{array}$ & $\begin{array}{l}46.0 \pm 7.04 \\
P=0.0856 \\
P 1=0.0048\end{array}$ & $\begin{array}{l}56.75 \pm 14.62 \\
\mathrm{P}=0.5839 \\
\mathrm{P} 1=0.7978\end{array}$ \\
\hline $10 \%$ ATV-Sol & $\begin{array}{l}68.0 \pm 6.44 \\
P=0.7435 \\
P 1=0.7435\end{array}$ & $\begin{array}{l}352.8 \pm 169.16 \\
P=0.0018 \\
P 1=0.2747\end{array}$ & $\begin{array}{l}115.0 \pm 15.94 \\
P=0.0007 \\
P 1=0.2765\end{array}$ & $\begin{array}{l}126.75 \pm 3.11 \\
\mathrm{P}=0.3577 \\
\mathrm{P} 1=0.0133\end{array}$ & $\begin{array}{l}52.8 \pm 2.28 \\
P=0.0706 \\
P 1=0.0006\end{array}$ & $\begin{array}{l}58.50 \pm 4.56 \\
P=0.4232 \\
P 1=0.6091\end{array}$ \\
\hline 20\%ATV-Sol & $\begin{array}{l}65.6 \pm 4.22 \\
P=0.6472 \\
P 1=0.2707\end{array}$ & $\begin{array}{l}404.6 \pm 189.63 \\
P=0.0002 \\
P 1=0.0615\end{array}$ & $\begin{array}{l}107.6 \pm 16.86 \\
P=0.0026 \\
P 1=0.5643\end{array}$ & $\begin{array}{l}80.00 \pm 22.97 \\
\mathrm{P}=0.0219 \\
\mathrm{P} 1=0.4779\end{array}$ & $\begin{array}{l}52.0 \pm 6.71 \\
P=0.1059 \\
P 1=0.0532\end{array}$ & $\begin{array}{l}70.50 \pm 9.50 \\
P=0.0152 \\
P 1=0.0297\end{array}$ \\
\hline Blank-NE & $\begin{array}{l}66.5 \pm 1.50 \\
P=0.8699 \\
P 1=0.4157\end{array}$ & $\begin{array}{l}218.0 \pm 7.18 \\
P=0.2139 \\
P 1=0.2999\end{array}$ & $\begin{array}{l}87.33 \pm 12.36 \\
\mathrm{P}=0.0735 \\
\mathrm{P} 1=0.3979\end{array}$ & $\begin{array}{l}96.00 \pm 4.64 \\
P=0.2122 \\
P 1=0.6694\end{array}$ & $\begin{array}{l}52.5 \pm 8.79 \\
\mathrm{P}=0.9780 \\
\mathrm{P} 1=0.0341\end{array}$ & $\begin{array}{l}96.33 \pm 1.63 \\
P=0.0000 \\
P 1=0.0000\end{array}$ \\
\hline
\end{tabular}

$\overline{\mathrm{x}} \pm \mathrm{SD}$. One-factor ANOVA and measuring the $\mathrm{p}$-values for the pairwise t-test was used; $\mathrm{P}$ value versus control; $\mathrm{P} 1$ value versus untreated group; $\mathrm{P}$ value $<0.05$ is considered significant.

Table 5: Total antioxidant capacity (TAC) and Lipid peroxidation (MDA) in all groups.

\begin{tabular}{|ll|l|}
\hline Group & $\begin{array}{l}\text { TAC } \\
(\mathbf{m M})\end{array}$ & $\begin{array}{l}\text { MDA } \\
(\boldsymbol{\mu M})\end{array}$ \\
\hline Control & $0.25 \pm 0.02$ & $1.63 \pm 0.13$ \\
\hline \multirow{2}{*}{ Untreated } & $\begin{array}{l}0.27 \pm 0.03 \\
\mathrm{P}=0.8114\end{array}$ & $\begin{array}{l}1.75 \pm 0.18 \\
\mathrm{P}=0.5993\end{array}$ \\
\hline \multirow{2}{*}{ 10\%ATV-LNE } & $\begin{array}{l}0.24 \pm 0.06 \\
\mathrm{P}=0.7736\end{array}$ & $\begin{array}{l}1.71 \pm 0.17 \\
\mathrm{P}=0.6818\end{array}$ \\
& $\mathrm{P} 1=0.5993$ & $\mathrm{P} 1=0.5993$ \\
\hline \multirow{2}{*}{ 20\%ATV-LNE } & $0.25 \pm 0.02$ & $1.59 \pm 0.07$ \\
& $\mathrm{P}=0.8635$ & $\mathrm{P}=0.6988$ \\
& $\mathrm{P} 1=0.6818$ & $\mathrm{P} 1=0.6818$ \\
\hline \multirow{2}{*}{ 10\%ATV-Sol } & $0.25 \pm 0.05$ & $1.62 \pm 0.14$ \\
& $\mathrm{P}=0.8818$ & $\mathrm{P}=0.6988$ \\
& $\mathrm{P} 1=0.6988$ & $\mathrm{P} 1=0.6988$ \\
\hline \multirow{2}{*}{ 20\%ATV-Sol } & $0.35 \pm 0.19$ & $1.73 \pm 0.08$ \\
& $\mathrm{P}=0.0640$ & $\mathrm{P}=0.1026$ \\
& $\mathrm{P} 1=0.1026$ & $\mathrm{P} 1=0.1026$ \\
\hline \multirow{2}{*}{ Blank-NE } & $0.26 \pm 0.02$ & $1.73 \pm 0.15$ \\
& $\mathrm{P}=0.9921$ & $\mathrm{P}=0.8190$ \\
& $\mathrm{P} 1=0.8190$ & $\mathrm{P} 1=0.8190$ \\
\hline
\end{tabular}

Data were expressed as $\overline{\mathrm{x}} \pm \mathrm{SD}$

\section{Kidney functions}

The CRE level of untreated group was significantly increased compared to control group. Whereas, a significant decrease in CRE levels were observed in all treated groups compared to untreated group except $10 \%$ ATV-Sol. It is noteworthy to mention that the
10\%ATV-LNE, 20\%ATV-LNE and 20\%ATV-Sol groups presented a least significant change from the normal group (Table 4). There were no significant changes in URC between the studied groups except in 20\%ATV-Sol compared to the untreated group.

\section{Estimation of oxidative stress markers}

TAC of 20\%ATV-Sol group was non-significantly higher than 10\%ATV-Sol, 10 and 20\% ATV-LNE groups (Table 5).

\section{Histopathological results}

Liver

Liver of the control and Blank-NE groups showed intact structure. On the other hand, liver of the untreated group showed marked fatty deposition in hepatocytes especially at the periphery of lobules near the portal regions. Engorged or congested central vein (CV) and blood sinusoids spaces were observed (Figure 3).

Administration of $10 \%$ of ATV with Loaded NE resulted in decreased lipid droplets observed in the hepatocytes. Some hepatocytes appeared degenerated with small nuclei while others showed enlarged nuclei. Liver of the group received 20\% ATV-LNE showed more or less intact hepatocytes with no lipid deposition. Liver of the rats received 10\% ATV-Sol and 20\% of ATV-Sol showed that most of the hepatocytes have no signs of lipid deposition and some of blood sinusoids were dilated. 


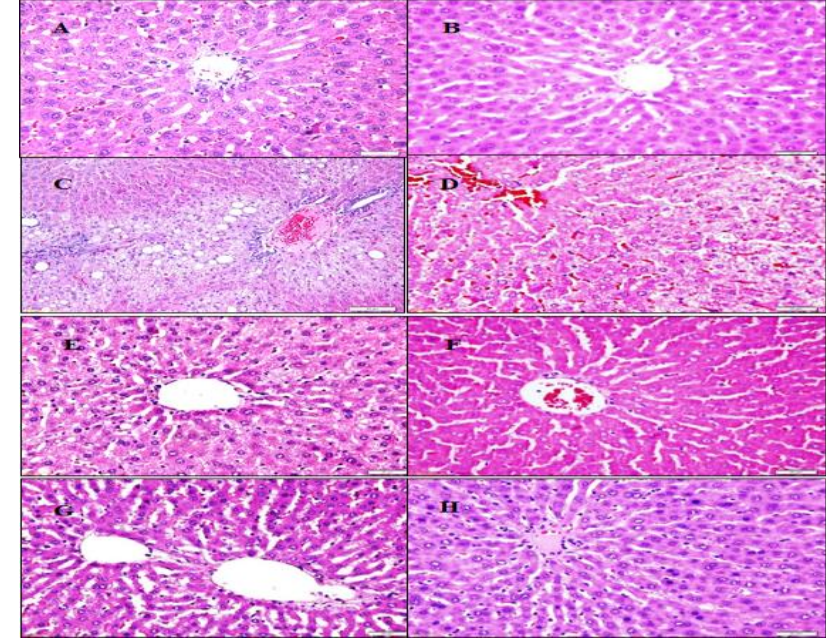

The marked decrease in lipid deposition in all treated groups

Figure 3: (A): The histopathological structure of liver control (B): Blank-NE; (C, D): untreated; (E): 10\%ATV-LNE; (F): 20\%ATV-LNE; (G) 10\%ATVSol; (H): $20 \%$ ATV-Sol.

\section{Kidney}

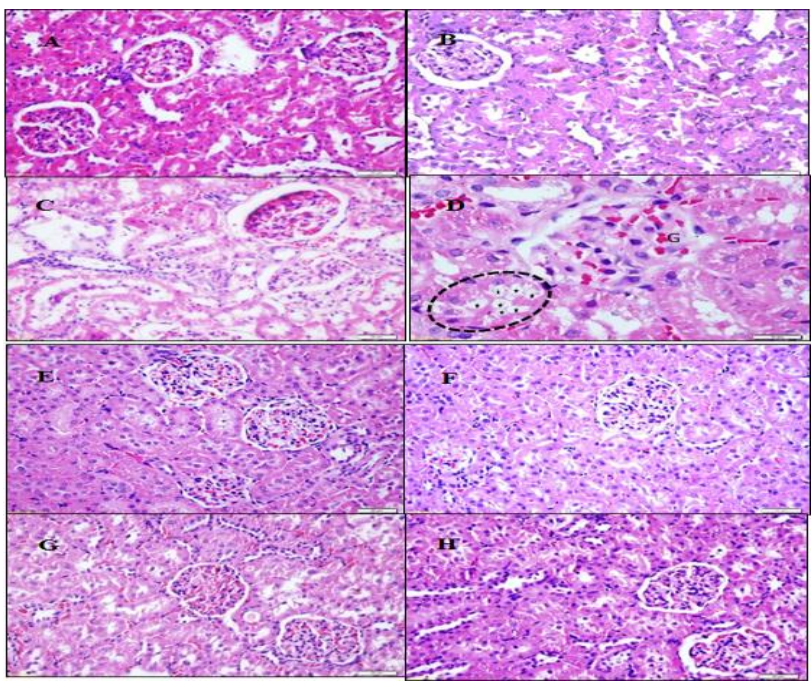

Figure 4: (A): The histopathological structure of liver control (B): Blank-NE; (C, D): untreated; (E): 10\%ATV-LNE; (F): 20\%ATV-LNE; (G) 10\%ATVSol; (H): $20 \%$ ATV-Sol.

Kidney of the control and Blank-NE groups showed intact renal cortex. On the other hands, some renal corpuscles of the untreated group showed damaged outer layer of Bowman capsule, congestion and dilatation of glomerular capillaries. Some proximal convoluted tubules (PCTs) were dilated. When it came to the treated groups, it was noticed that renal cortex of the rats all treated groups appeared intact (Figure 4).

\section{DISCUSSION}

One of the most common drugs to treat the hyperlipidemia is atorvastatin, one of the statins which are among the safest classes of drugs used on the long-term. ${ }^{18}$ The oral bioavailability of atorvastatin is only $12 \%$ and its poor solubility in water. ${ }^{19}$ The objective of the present study was to increase the solubility of ATV by loading it on nanoemulsion carrier, hence increase its bioavailability and reduced their side effects. The ATV formulations activity was evaluated by measuring the body weight change, serum biochemical parameters and oxidative stress markers.

In this study, the morphology characterization, viewed by the SEM, detected that $10 \%$ and 20\% ATV-LNE were spherical shape and this finding was supported by some previous studies. ${ }^{20}$ The particle sizes of ATV-LNE ranged from $38.12 \pm 6.71$ to $119.2 \pm 16.17 \mathrm{~nm}$ which was similar to the results observed by Kumar who reported the particle size of ATV loaded solid lipid nanoparticles was ranged from $50.0 \pm 4.12$ to $125.1 \pm 6.12 \mathrm{~nm}^{21}$

The particle size of $20 \%$ ATV-LNE has the smallest size with $\mathrm{z}$-average diameter of $38.12 \pm 6.71 \mathrm{~nm}$ and has the largest zeta negative potential of $-26.8 \pm 4.16 \mathrm{mV}$. So that achieved the purpose to obtain nanoemulsions with small particle sizes, hence increase bioavailability and enable targeting. ${ }^{23}$ The polydispersity index for ATV-LNE formulations was ranged from 0.128 to 0.176 , indicates that the preparations have a very narrow polydispersity which less than 0.5 , the characteristic highly desirable in drug delivery applications. ${ }^{23}$ this was in agreement with Rohilla et al. who found the PDI of ATV loaded in glycyrrhetinic acid-chitosan nanoparticles was $0.126 .^{20}$

When investigating the lipid profile, it was noticed that the cholesterol and LDL levels were decreased in all treated groups slightly. 20\% ATV-LNE and Blank-NE groups have the least level of $\mathrm{CHO}$ and LDL compared to the control group. This result was in agreement with other studies that showed decreased serum levels of $\mathrm{CHO}$ and LDL following the administration of ATV in solid dispersions (SDs) form compared to the corresponding physical mixtures (PMs). ${ }^{24}$

There was approximately equal improvement on all treated groups, in this study, regarding to HDL levels except $20 \%$ ATV-Sol group showed the highest HDL level. Several clinical trials reported HDL increasing beneficial effect of atorvastatin. ${ }^{25}$ These results were in agreement with those of Meena who reported that treatment with commercial formulation of atorvastatin calcium (Lipicure) and Poly lactideco-glycolic acid (PLGA) nanoparticles formulations had shown almost equal effects in reducing levels of CHO, TG, LDL-C and elevated HDL-C levels. ${ }^{5}$ Nanoparticles have been reported to increase the absorption of the encapsulated drugs when compared to the suspension form or any simple formulation type of the drug. ${ }^{26}$

Atorvastatin has pleiotropic effect through insulin sensitization as it reduces the glucose levels to some extent. $^{5}$ In the present study, the 10\%ATV-LNE and $20 \%$ ATV-LNE groups reduced serum glucose levels 
compared to all groups especially ATV-Sol groups. In contrast, the serum insulin levels showed no significant differences between all studied groups excepting BlankNE group showed an increase compared to normal and $20 \%$ ATV-LNE groups. It was found that the alginate/chitosan-coated nanoemulsion of insulin lowered glucose levels of diabetic rats and increased the bioavailability of insulin, which showed a good insulin intestinal absorption. ${ }^{27}$

When it came to the effect of different studied drug formulations on the liver functions, it was observed that ALT levels in all treated groups showed a highly significant increase than the normal group. Regarding to AST levels, data showed an increase in all groups except 20\% ATV-Sol and Blank-NE groups. The results obtained were similar to those results of a study done by Meena who declared that treatment with commercial formulation (Lipicure $\AA$ ) showed an increase in AST levels in hyperlipidemic rats. ${ }^{5}$ Furthermore, several studies reported that treatment with lipitor commercial formulation cause an elevation in ALT and AST activities more than $3 X$ upper normal limits. ${ }^{28}$ Although statins appear safe, animal and pre-marketing clinical trials are shown signs of liver toxicity, mostly manifesting as minor elevations in aminotransferase concentrations. ${ }^{29}$ In patients on statins, mild elevation of liver enzymes are observed in 1-3\% of cases, but in the vast majority of patients this was not clinically significant and there is no need for discontinuation of therapy. ${ }^{31}$ When it came to the histopathological assessment of different drug formulations on the liver, the present study revealed that the remarkable deposition of fatty droplets in hepatocytes and the congestion observed in the central vein and blood sinusoids of liver from rats received HFD and left without treatment were markedly reduced after treatment with $10 \%$ and 20\% ATV-Sol apart from few lipid droplet. Interestingly, administration of $20 \%$ ATV- LNE prevent lipid deposition in the liver. Those results are in agreement with those of Jahangiri who reported that treatment with ATV especially its solid dispersions (SDs) form could outstandingly reduce the HFD harmful effects on the liver. $^{24}$

It was observed that the serum creatinine level of untreated group was significantly higher than the control group, which are indicative of muscle as well as kidney affection that was not observed with nanoparticles formulations. It is noteworthy to mention that treatment with ATV formulations either NEs or solutions showed remarkable decrease in serum CRE compared to untreated group. Meena reported a similar result induced by lipicure nanoparticles formulations. ${ }^{5}$ Histopathological examination of kidney from untreated HFD-fed group showed damage of some renal corpuscles and congestion of some glomerular capillaries as well as tubular affection. These findings were supported by those of Ayoub who reported that HFD increased blood glucose, insulin and disturbed the lipid profile. ${ }^{31}$ They added that HFD induced congestion of glomerular capillaries and widening of the
Bowman's capsule. Administration of $10 \%$ and $20 \%$ ATV-Sol to hyperlipedimic rats were found to preserve renal glomerular and tubular structure apart from mild congestion of glomerular capillaries. In a previous study of Aktas wistar albino rats treated with ATV showed normal histologic structure of the kidney. ${ }^{32}$

No significant differences existed between TAC and MDA levels in the different drug formulations compared to the control and untreated groups. The TAC level of 20\%ATVSol group was higher than 10\%ATV-Sol, 10 and $20 \%$ ATV-LNE groups. An interesting finding is, 20\% ATVLNE decreased MDA level which is a marker of oxidative stress.

\section{CONCLUSION}

In this study, the nanoemulsion could be a promising carrier to enhance the oral bioavailability of atorvastatin and increased its solubility. The nanoemulsion formula, consisted of mixture of surfactants (SO, SPC and EU), 1octanol ac cosurfactant, tris-HCL buffer as aqueous phase and $\mathrm{CHO}$ as oil phase. $20 \%$ ATV-LNE was found to be the most effective formulation of atorvastatin as it improved lipid profile, serum glucose and insulin levels and preserve both liver and kidney function and structure.

Funding: Funding sources from King Abdulaziz City for Science and Technology (KACST)

Conflict of interest: None declared

Ethical approval: The study was approved by the Institutional Ethics Committee

\section{REFERENCES}

1. Mishra PR, Panda PK, Korla A, Panigrahi S. Evaluation of acute hypolipidemic activity of different plant extracts in triton $\mathrm{Wr} 1339$ induced hyperlipidemia in albino rats. Pharmacologyonline. 2011;3:925-34.

2. Rodgers M. An Analysis of the Cause, Effect and Control of Hyperlipidemia from a Nursing Perspective. 2014.

3. Shattat GF. A Review Article on Hyperlipidemia: Types, Treatments and New Drug Targets. Biomedical and Pharmacology Journal. 2014;7:399-409.

4. Maji D, Shaikh S, Solanki D, Gaurav K. Safety of statins. Indian J Endocrinol Metab. 2014;17:636.

5. Meena A, Ratnam DV, Chandraiah G, Ankola D, Rao PR, Kumar MR. Oral nanoparticulate atorvastatin calcium is more efficient and safe in comparison to Lipicure ${ }^{\circledR}$ in treating hyperlipidemia. Lipids. 2008;43:231-41.

6. Shitara Y, Sugiyama Y. Pharmacokinetic and pharmacodynamic alterations of 3-hydroxy-3methylglutaryl coenzyme A (HMG-CoA) reductase inhibitors: drug-drug interactions and interindividual differences in transporter and metabolic enzyme functions. Pharmacol Therap. 2006;112:71-105. 
7. Lea AP, Mctavish D. Atorvastatin. A review of its pharmacology and therapeutic potential in the. Drugs. 1997;53:828-47.

8. Wilczewska AZ, Niemirowicz K, Markiewicz KH, Car H. Nanoparticles as drug delivery systems. Pharmacological reports. 2012;64:1020-37.

9. Nevozhay D, Kańska U, Budzyńska R, Boratyński J. Current status of research on conjugates and related drug delivery systems in the treatment of cancer and other diseases. Postepy higieny i medycyny doswiadczalnej. 2006;61:350-60.

10. Shang L, Nienhaus K, Nienhaus GU. Engineered nanoparticles interacting with cells: size matters. J Nanobiotech. 2014;12:1.

11. Mason TG, Wilking J, Meleson K, Chang C, Graves S. Nanoemulsions: formation, structure, and physical properties. Journal of Physics: 2006;18:R635.

12. Liu P, Kurihara-Bergstrom T, Good WR. Cotransport of estradiol and ethanol through human skin in vitro: understanding the permeant/enhancer flux relationship. Pharmaceutical research. 1991;8:938-44.

13. Kadu PJ, Kushare SS, Thacker DD, Gattani SG. Enhancement of oral bioavailability of atorvastatin calcium by self-emulsifying drug delivery systems (SEDDS). Pharm Develop Technol. 2011;16:65-74.

14. Alkhatib MH, Albishi HM. In vitro evaluation of antitumor activity of doxorubicin-loaded nanoemulsion in MCF-7 human breast cancer cells. Journal of nanoparticle research. 2013;15:1-15.

15. Chouksey R, Pandey H, Jain A, Soni H, Saraogi G. Preparation and evaluation of the self-emulsifying drug delivery system containing atorvastatin HMGCoA inhibiter. Int J Pharm Pharm Sci. 2011;3:147-52.

16. Alkhatib MH, Al-qaidi WA. Cytotoxicity effect of docetaxel-loadedmicroemulsion in A-549 non-small cell lung cancer and HCT116 colon cancer cells. Int J Pharm Bio Sci. 2014;5:300-15.

17. Basuny AM, Gaafar AM, Arafat SM. Tomato lycopene is a natural antioxidant and can alleviate hypercholesterolemia. African J Biotech. 2009;8.

18. Pedersen TR. Lipids: HDL, LDL, Role in Primary Prevention, the Message from Trials? Atherosclerosis: The 21st Century Epidemic. 2010;65.

19. Ahjel SW, Lupuleasa D. Enhancement of solubility and dissolution rate of different forms of atorvastatin calcium in direct compression tablet formulas. Farmacia. 2009;57:290-300.

20. Rohilla R, Garg T, Bariwal J, Goyal AK, Rath G. Development, optimization and characterization of glycyrrhetinic acid-chitosan nanoparticles of atorvastatin for liver targeting. Drug delivery. 2016;23:2290-7.
21. Kumar PP, Gayatri P, Sunil R, Jaganmohan S, Rao YM. Atorvastatin loaded solid lipid nanoparticles: formulation, optimization, and in vitro characterization. IOSR J Pharm. 2012;2:23-32.

22. Lovelyn C, Attama AA. Current state of nanoemulsions in drug delivery. $\mathrm{J}$ Biomat Nanobiotech. 2011;2:626.

23. Bathool A, Vishakante GD, Khan MS, Shivakumar H. Development and characterization of atorvastatin calcium loaded chitosan nanoparticles for sustain drug delivery. Adv Mat Lett. 2012;3:466-70.

24. Jahangiri A, Barzegar-Jalali M, Garjani A, Javadzadeh $\mathrm{Y}$, Hamishehkar $\mathrm{H}$, Afroozian $\mathrm{A}$, et al. Pharmacological and histological examination of atorvastatin-PVP K30 solid dispersions. Powder Technology. 2015;286:538-45.

25. Rogers SL, Magliano DJ, Levison DB, Webb K, Clarke PJ, Grobler MP, et al. A dose-specific metaanalysis of lipid changes in randomized controlled trials of atorvastatin and simvastatin. Clini Therapeut. 2007;29:242-52.

26. Omar MA, Wilson JP, Cox TS. Rhabdomyolysis and HMG-CoA reductase inhibitors. Ann Pharmacotherap. 2001;35:1096-107.

27. Li X, Qi J, Xie Y, Zhang X, Hu S, Xu Y, et al. Nanoemulsions coated with alginate/chitosan as oral insulin delivery systems: preparation, characterization, and hypoglycemic effect in rats. Inte J Nanomed. 2013;8:23.

28. Smith CC, Bernstein LI, Davis RB, Rind DM, Shmerling RH. Screening for statin-related toxicity: the yield of transaminase and creatine kinase measurements in a primary care setting. Arch Internal Med. 2003;163:688-92.

29. Tolman K. Lovastatin and the liver. Am J Cardiol. 2002;89:1374-80.

30. Bader T. Liver tests are irrelevant when prescribing statins. The Lancet. 2010;376:1882-3.

31. Ayuob, NN. Can raisins ameliorate hypercholesterolemia-induced nephropathy? What is the evidence? The Egyptian Journal of Histology. 2014;37:677-88.

32. Aktas A, Tasdemir MS, Tuncer MC, Nergiz Y, Akkus M, Bagriyanik HA, et al. Atorvastatin has no effects on kidney tissues of wistar albino rats in the long-term Intake: an electron microscopic Study. Int J Morphol. 2011;29:144-50.

Cite this article as: Balamash KS, Al-ddyni MS. Biochemical and histopathological assessment of atorvastatin-loaded nanoemulsion effectiveness in Rats. Int J Basic Clin Pharmacol 2018;7:221-8. 